\title{
Review \\ Sildenafil Supplementation for Women Undergoing Infertility Treatments: A Systematic Review and Meta-Analysis of Randomized Controlled Trials
}

\author{
Loris Marin ${ }^{1}\left(\mathbb{D}\right.$, , Alessandra Andrisani ${ }^{1}$, Luciana Bordin ${ }^{2}$, Francesco Dessole ${ }^{3}$, Marco Noventa ${ }^{1, *}$, \\ Amerigo Vitagliano ${ }^{1}$, Giampiero Capobianco ${ }^{3}$ and Guido Ambrosini ${ }^{1}$
}

check for updates

Citation: Marin, L.; Andrisani, A.; Bordin, L.; Dessole, F.; Noventa, M.; Vitagliano, A.; Capobianco, G.; Ambrosini, G. Sildenafil Supplementation for Women Undergoing Infertility Treatments: A Systematic Review and Meta-Analysis of Randomized Controlled Trials. J. Clin. Med. 2021, 10, 4346. https://doi.org/10.3390/ jcm10194346

Academic Editor:

Kanna Jayaprakasan

Received: 10 August 2021

Accepted: 20 September 2021

Published: 24 September 2021

Publisher's Note: MDPI stays neutral with regard to jurisdictional claims in published maps and institutional affiliations.

Copyright: (c) 2021 by the authors. Licensee MDPI, Basel, Switzerland. This article is an open access article distributed under the terms and conditions of the Creative Commons Attribution (CC BY) license (https:// creativecommons.org/licenses/by/ $4.0 /)$.
1 Department of Women's and Children's Health, University of Padua, 35128 Padua, Italy; loris.marin@unipd.it (L.M.); alessandra.andrisani@unipd.it (A.A.); vitagliano@gmail.com (A.V.); guido.ambrosini@unipd.it (G.A.)

2 Department of Molecular Medicine-Biological Chemistry, University of Padova, 35131 Padova, Italy; luciana.bordin@unipd.it

3 Department of Surgical, Microsurgical and Medical Sciences, Gynecologic and Obstetric Clinic, University of Sassari, 07100 Sassari, Italy; francescodessole@gmail.com (F.D.); capobianco@gmail.com (G.C.)

* Correspondence: marconoventa.md@gmail.com; Tel.: +39-476-527-255

\begin{abstract}
The aim of this systematic review and meta-analysis is to summarize data on the effectiveness of Sildenafil supplementation for women undergoing assisted reproduction techniques. This meta-analysis of randomized controlled trials (RCTs) evaluates the effects of Sildenafil administration during infertility treatments compared with a control group in infertile women. Outcomes evaluated were endometrial thickness (ETh) and the clinical pregnancy rate (CPR). The chemical pregnancy rate (ChPR) was also evaluated. Pooled results were expressed as the risk ratio (RR) or mean differences (MD) with a $95 \%$ confidence interval (95\% CI). Women undergoing ovulation induction who received Sildenafil showed higher ETh and a higher CPR in comparison to controls. In this group, both the ETh and ChPR resulted in significantly higher values only with delayed start administration. Women undergoing fresh or frozen embryo transfer who received Sildenafil showed no significant advantages regarding ETh and CPR in comparison to controls. In this group, we found a significantly higher $\mathrm{ChPR}$ in women receiving Sildenafil. A subgroup analysis revealed significant advantages regarding ETh with oral administration for women undergoing fresh or frozen embryo transfer. Sildenafil therapy appears to improve endometrial thickness and pregnancy rate in women undergoing timed intercourses but it resulted not effective in IUI and IVF treatments. Further RCTs with rigorous methodology are still mandatory.
\end{abstract}

Keywords: Sildenafil; endometrial thickness; timed intercourse; intrauterine insemination; in vitro fertilization

\section{Introduction}

Despite advances in assisted reproductive technologies (ARTs), the cumulative success rate of the procedures remains suboptimal, with an estimated overall pregnancy rate of around 30\% [1]. According to several studies, one of the major limiting factors for the success of ART might be represented by impaired endometrial receptivity (ER) [2].

Despite all efforts to validate specific and effective markers to find an optimal window of implantation for embryo transfer [3], endometrial thickness (ETh) is still considered the best surrogate measurement and a crucial factor for implantation. Accordingly, several studies reported a direct correlation between low ETh $(<7 \mathrm{~mm})$ and low success rates of ARTs - and medically assisted reproduction-(MAR) procedures, including intrauterine insemination (IUI) and in vitro fertilization (IVF) with fresh embryo transfer (fresh-ET) or frozen embryo transfer (frozen-ET) [4-6]. 
During the last decades, several strategies (including hormonal and non-hormonal adjuvants) have been tested with the purpose of increasing ETh in women undergoing infertility treatments, with conflicting results [7-17].

One of the adjuvants that showed potential beneficial effects on endometrial thickening in women undergoing infertility treatments is sildenafil citrate, a 5-phosphodiesterase inhibitor widely used for male erectile dysfunction [18]. The Sildenafil pharmacological effect of Sildenafil is based on the prevention of cGMP breakdown thereby increasing smooth muscle relaxation and vasodilation [18]. At the endometrium level, Sildenafil may increase uterine artery flow and exert a positive effect on endometrial growth in response to estrogenic stimulation [19]. Moreover, it may improve endometrial tolerance to the embryo through decreasing local natural killer cell activity and favoring the accomplishment of proper embryo implantation [20]. Mechanisms of action of Sildenafil on the endometrium are not fully understood. Due to its supposed action of favoring implantation both through the increase in endometrial thickness [19] and through the immune action [20], this type of add-therapy has been studied on different types of infertile women, both those with a thin endometrium and those without an apparent endometrial problem. In fact, implantation does not occur in about $1 / 3$ of transfers of euploid blastocyst in women without an apparent endometrial abnormality [21].

Based on these principles, randomized controlled trials investigated the efficacy of oral or vaginal Sildenafil administration in women undergoing infertility treatments. Thus, the aim of this present systematic review and meta-analysis was to summarize the current evidence on the effectiveness of Sildenafil administration for improving ETh and the success of ARTs and MAR procedures.

\section{Material and Methods}

\subsection{Study Design}

This is a systematic review and meta-analysis of RCTs evaluating the effectiveness of add-therapy with Sildenafil in MAR and ARTs procedures. The study protocol was registered in PROSPERO before the start of the literature search (CRD42020165583). The review was written following the Preferred Reporting Items for Systematic Reviews and Meta-Analyses (PRISMA) guidelines [22].

\subsection{Search Strategy}

A literature search was conducted on electronic databases (Medline, Scopus, Embase, ScienceDirect, the Cochrane Library, Clinicaltrials.gov, Cochrane Central Register of Controlled Trials, EU Clinical Trials Register and World Health Organization International Clinical Trials Registry Platform) up to April 2021. Key search terms included the following: "sildenafil" (Mesh) AND "infertility" OR "timed intercourse" OR "intrauterine insemination" OR "in-vitro fertilization" OR "assisted reproductive technology" OR "controlled ovarian stimulation" OR "fresh embryo transfer" OR "frozen embryo transfer".

\subsection{Inclusion Criteria}

- Language: studies reported in English language

- Study designs: randomized controlled trials

- Population: infertile women undergoing MAR and ARTs procedures, including TI, IUI and IVF with fresh fresh-ET or Frozen-ET.

- Intervention: Sildenafil therapy

- Timing of intervention: during the monitored cycle for TI or IUI; during the course of controlled ovarian stimulation (COS) for IVF and fresh_ET and during the course of endometrial preparation for frozen_ET.

- Comparator: infertile women with unexplained infertility and with ovulatory or anovulatory cycles, with thin endometrium or with multiple failed ART cycles, undergoing TI or IUI or COS with fresh_ET embryo transfer or endometrial preparation for frozen-ET 
- $\quad$ Outcomes and their definitions: endometrial thickness (ETh-transvaginal ultrasonography measurement of the endometrium at the maximal distance between each myometrial/endometrial interface in a prearranged moment of the menstrual cycle), clinical pregnancy rate (CPR-per woman randomized, defined as the presence of a gestational sac on transvaginal ultrasound), chemical pregnancy rate (ChPR-per woman randomized, defined as serum measurement of beta Human chorionic gonadotropin $>5 \mathrm{mU} / \mathrm{mL}$ ).

\subsection{Study Selection and Data Extraction}

Two authors (L.M., A.V.) independently screened titles and abstracts of studies obtained by the search strategy. The text of each potentially relevant study was assessed for inclusion in the review, independently by the two authors. A manual search of reference lists of retrieved studies and available review articles was also performed to avoid missing relevant publications. The same authors have independently extracted data from the studies. One other author (A.A.) reviewed the selection and data extraction process. We searched for published and unpublished studies from the aforementioned electronic databases. The results were compared, and any disagreement was resolved by consensus.

\subsection{Risk of Bias}

Two authors (L.M., A.V.) independently judged the methodological quality of the included studies by using the criteria reported in the Cochrane's Handbook for Systematic Reviews of Interventions. Seven specific domains related to risk of bias were assessed, which are as follows: random sequence generation, allocation concealment, blinding of participants and personnel, blinding of outcome assessment, incomplete outcome data, selective data reporting and other bias.

Authors' judgements were expressed as "low risk", "high risk", or "unclear risk" of bias. For the estimation of "selective data reporting", we evaluated study protocols, when available. If protocol was not available, studies have been judged at high risk of bias.

\subsection{Statistical Analysis}

Two authors (M.N, L.M.) independently performed the data analysis using Review Manager (version 5.3). All analyses were performed with the random-effects model (by DerSimonian and Laird), with an intention-to-treat approach. Variables were compared using the risk ratio (RR) or mean differences (MD), with a 95\% confidence interval (95\% CI). A $p$ value lower than 0.05 was considered as statistically significant. Heterogeneity was measured with the Higgins I2.

When possible, we performed a subgroup analysis to evaluate the influence of intervention (Sildenafil treatment) based on the timing of administration (started with ovarian stimulation versus delayed start, 7-8 days from ovarian stimulation) or the route of administration (vaginal versus oral route).

Concerning specific outcomes, in cases of studies with missing data about ChPR but data about CPR, we decided to consider CPR as a surrogate measurement of ChPR.

Risk of bias across studies was not measured due to the low number of studies included (according to the Cochrane's Handbook recommendation).

\section{Results}

\subsection{Study Selection}

The electronic searches provided a total of 656 citations. After the removal of 100 duplicate records, 556 citations remained. Of these, 528 records were excluded after title/abstract screening (not relevant to the review). We examined the full text of 28 manuscripts, and, of these, we excluded 16 papers - two trials investigated Tadalafil as the 5-phosphodiesterase inhibitor [23,24], two trials reporting not analyzable data (only abstracts available) $[25,26]$, four papers because the design was retrospective [27-30], six because of the observational design [31-34], one paper because it was a review [35]. Another 
paper was excluded because the results of Sildenafil efficacy in women with unexplained infertility were provided based on a subgroup analysis (duration of infertility) only, and the size of the subgroups was not described [36].

Finally, 12 manuscripts were included in the meta-analysis (see Figure 1: Prisma Flow Diagram). We analyzed all outcomes according to the assisted reproductive technique used. Considering the number of included studies, we performed analyses firstly together and then separately by TI/IUI (TI/IUI group) [19,37-41] and IVF fresh-ET and frozen-ET (IVF fresh-ET/frozen-ET group) [12,42-46]. Full details about the included studies are available in Tables 1 and 2.

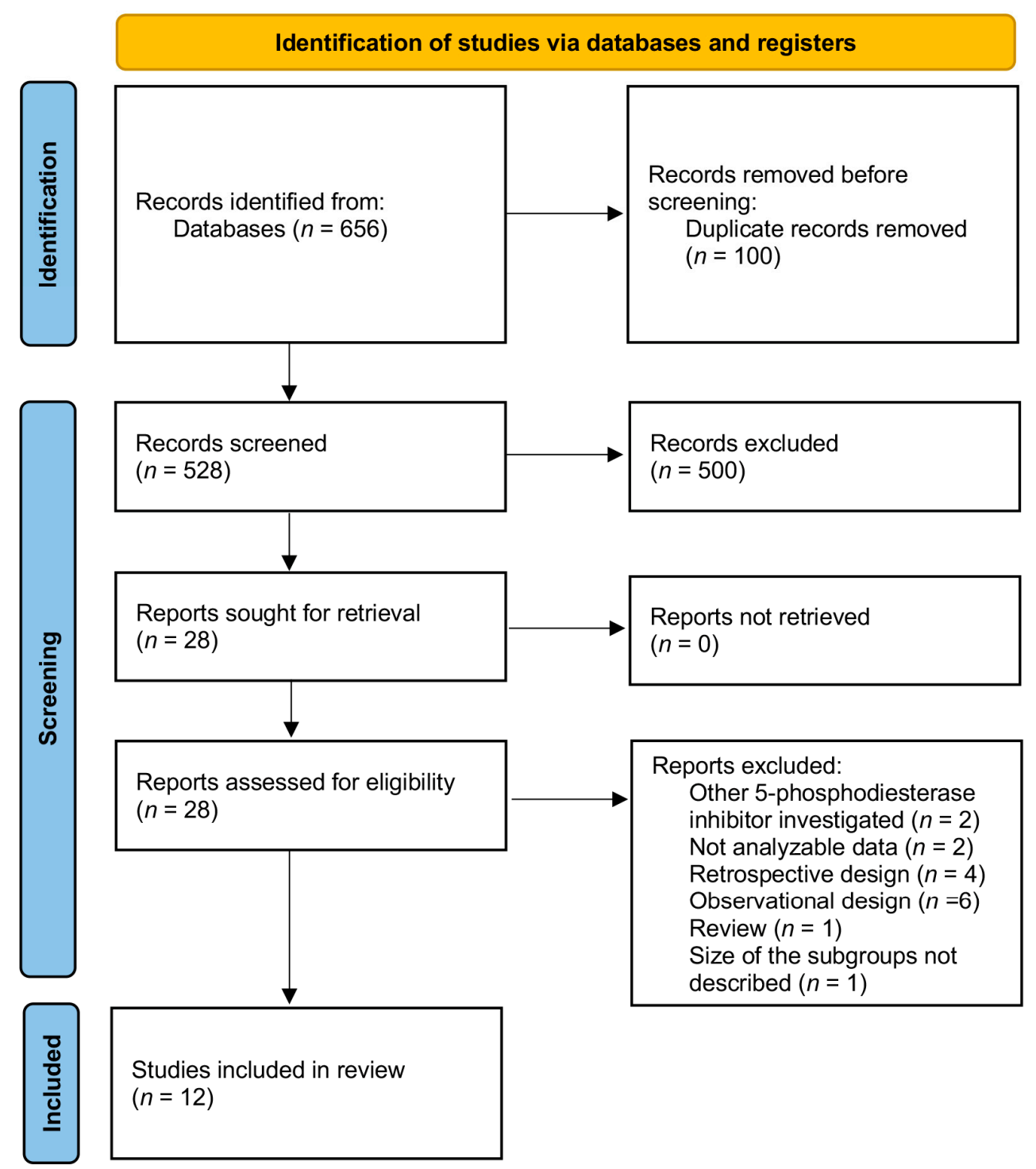

Figure 1. Prisma Flow Diagram. 


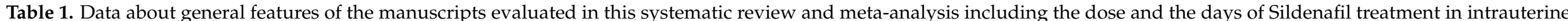
insemination cycles/timed intercourse cycles.

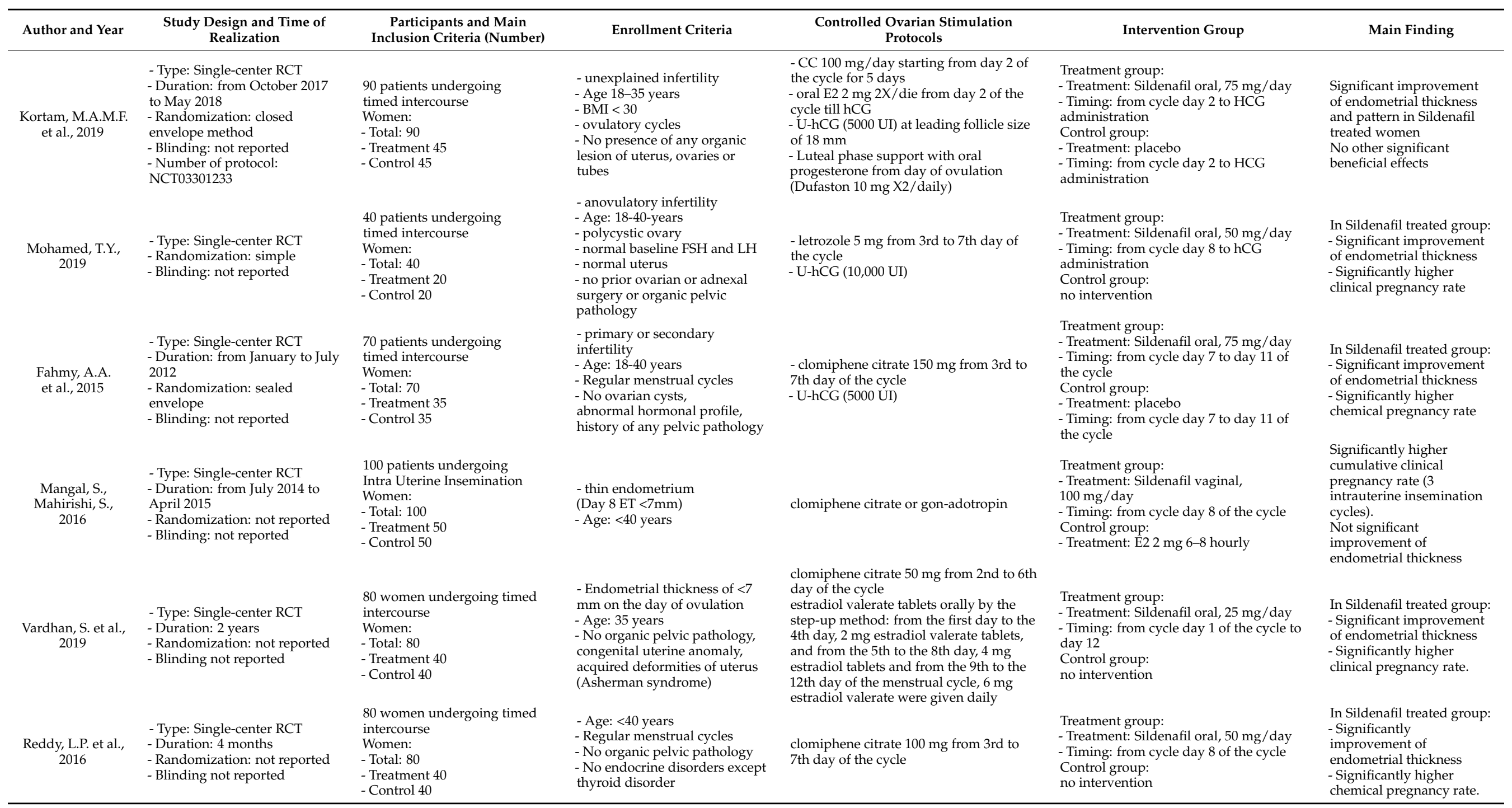




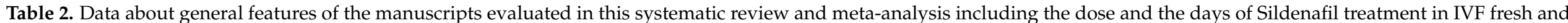
frozen embryo transfer cycles.

\begin{tabular}{|c|c|c|c|c|c|c|}
\hline Author and Year & $\begin{array}{c}\text { Study Design and Time of } \\
\text { Realization }\end{array}$ & $\begin{array}{c}\text { Participants and Main } \\
\text { Inclusion Criteria (Number) }\end{array}$ & Enrollment Criteria & $\begin{array}{c}\text { Controlled Ovarian } \\
\text { Stimulation Protocols }\end{array}$ & Intervention Group & Main Finding \\
\hline $\begin{array}{l}\text { Moini, A. et al., } \\
2020\end{array}$ & $\begin{array}{l}\text { - Type: Single-center RCT } \\
\text { - Duration: February } 2014 \text { to } \\
\text { November } 2016 \\
\text { - Randomization: random } \\
\text { allocation sequence generated } \\
\text { by a randomized block design } \\
\text { - Blinding: double-blind } \\
\text { - Number of protocol: } \\
\text { NCT03192709 }\end{array}$ & $\begin{array}{l}66 \text { patients undergoing IVF } \\
\text { fresh cycles } \\
\text { Intention to treat: } \\
\text { - Total: } 66 \\
\text { - Treatment A: } 22 \\
\text { - Treatment B: } 22 \\
\text { - Control: } 22 \\
\text { Per protocol: } \\
\text { - Total: } 66 \\
\text { - Treatment A: } 21 \\
\text { - Treatment B: } 18 \\
\text { - Control: } 17\end{array}$ & $\begin{array}{l}\text { - AMH }>1.5, \text { FSH }<10 \\
\text { - at least } 2 \text { consecutive failed } \\
\text { IVF-ET cycles with at least a } \\
\text { transfer of two good quality } \\
\text { embryos } \\
\text { - hCG day endometrial } \\
\text { thickness }<7 \mathrm{~mm} \text { in all prior } \\
\text { IVF/ICSI attempts } \\
\text { - Age } \leq 38 \text { years } \\
\text { - No history of myomectomy or } \\
\text { Asherman's syndrome } \\
\text { - normal endometrial } \\
\text { appearance }\end{array}$ & $\begin{array}{l}\text { - GnRH-ag long protocol } \\
\text { - FSH/FH +LH } \\
\text { - U-hCG }(10000 \mathrm{IU}) \text { at follicle } \\
\text { size } 18 \mathrm{~mm}(\geq 2) \text {. } \\
\text { - Oocyte retrieval } 36 \mathrm{~h} \text { after } \\
\text { hCG } \\
-2 / 3 \text { days embryos transfer } \\
\text { - Luteal phase support with } \\
\text { progesterone (100 } \mathrm{mg} \text { IM daily } \\
\text { or } 800 \mathrm{mg} \text { vaginal daily) }\end{array}$ & $\begin{array}{l}\text { Treatment group A: } \\
\text { - Treatment: Sildenafil vaginal, } 100 \mathrm{mg} / \text { day } \\
\text { - Timing: from cycle day } 1 \text { to OPU } \\
\text { Treatment group B: } \\
\text { - Treatment: Placebo then Sildenafil vaginal, } \\
100 \mathrm{mg} / \text { day } \\
\text { - Timing: placebo from cycle day } 1 \text { to } 2 \text { days } \\
\text { before hCG administration, then Sildenafil to } \\
\text { to OPU } \\
\text { Control group: } \\
\text { - Treatment: Placebo } \\
\text { - Timing: from cycle day } 1 \text { to OPU }\end{array}$ & No significant beneficial effects \\
\hline $\begin{array}{l}\text { Shahrokh, T.N.E. } \\
\text { et al., } 2018\end{array}$ & $\begin{array}{l}\text { - Type: Single-center RCT } \\
\text { - Randomization: simple } \\
\text { - Blinding: not reported }\end{array}$ & $\begin{array}{l}72 \text { patients undergoing IVF } \\
\text { fresh cycles } \\
\text { Women: } \\
\text { - Total: } 72 \\
\text { - Treatment } 36 \\
\text { - Control } 36\end{array}$ & $\begin{array}{l}-\geq 2 \text { failed IVF- ET cycles } \\
\text { - Age }<45 \text { years }(21-43)\end{array}$ & $\begin{array}{l}\text { - GnRH-ag long protocol } \\
\text { Buserelin } 1.5 \mathrm{mg} \text { daily } \\
\text { - FSH (dose according to } \\
\text { patients' characteristics) }\end{array}$ & $\begin{array}{l}\text { Treatment group: } \\
\text { - Treatment: Sildenafil vaginal, } 100 \mathrm{mg} / \text { day } \\
\text { - Timing: from cycle day } 2 \text { to HCG } \\
\text { administration } \\
\text { Control group: no intervention }\end{array}$ & $\begin{array}{l}\text { Significant improvement of } \\
\text { endometrial thickness in } \\
\text { Sildenafil treated women } \\
\text { No other significant beneficial } \\
\text { effects }\end{array}$ \\
\hline $\begin{array}{l}\text { Ataalla, W.M. } \\
\text { et al., } \\
2016\end{array}$ & $\begin{array}{l}\text { - Type: Single-center RCT } \\
\text { - Duration: from January } 2012 \\
\text { to January } 2014 \\
\text { - Randomization: women asked } \\
\text { to choose a number from } 1 \text { to } 60 \\
\text { - Blinding: double-blinded }\end{array}$ & $\begin{array}{l}60 \text { patients undergoing IVF } \\
\text { fresh cycles } \\
\text { Women: } \\
\text { - Total: } 60 \\
\text { - Treatment } 30 \\
\text { - Control } 30\end{array}$ & $\begin{array}{l}\text { - Age } \leq 35 \\
\text { - No ovarian surgery } \\
\text { - Low responders to COH: } \leq 3 \\
\text { follicles on the day of hCG } \\
\text { administration } \\
\text { or } \leq 3 \text { oocytes } \\
\text { - previous cycle cancellation } \\
\text { due to poor follicular } \\
\text { development }\end{array}$ & $\begin{array}{l}\text { - GnRH-antagonist protocol } \\
\text { - FSH } 300 \text { IU + } 150 \text { hMG from } \\
\text { 2nd day of cycle, dose adjusted } \\
\text { according patient } \\
\text { characteristics } \\
\text { - U-hCG (10,000 UI) at leading } \\
\text { follicle(s) size of } 17 \mathrm{~mm} \\
\text { - Oocyte retrieval } 34-36 \mathrm{~h} \text { after } \\
\text { hCG } \\
\text { - Day } 3 \text { embryos transferred } \\
\text { - Luteal phase support with } \\
\text { progesterone (150 mg IM daily) }\end{array}$ & $\begin{array}{l}\text { Treatment group: } \\
\text { - Treatment: Sildenafil oral, } 50 \mathrm{mg} / \text { day } \\
\text { - Timing: from cycle day } 1 \\
\text { Control group: } \\
\text { - Treatment: Placebo oral } \\
\text { - Timing: from cycle day } 1\end{array}$ & $\begin{array}{l}\text { Significant improvement of } \\
\text { endometrial thickness in } \\
\text { Sildenafil treated women. } \\
\text { No other significant beneficial } \\
\text { effects. }\end{array}$ \\
\hline $\begin{array}{l}\text { Firouzabadi, R.D. } \\
\text { et al. } \\
2013\end{array}$ & $\begin{array}{l}\text { - Type: Single-center RCT } \\
\text { - Duration: from } 2009 \text { to } 2011 \\
\text { - Randomization: random } \\
\text { numbers tables } \\
\text { - Blinding: not reported } \\
\text { - Number of protocol: } \\
\text { IRCT201210232575N3 } \\
\text { NCT01668446 }\end{array}$ & $\begin{array}{l}80 \text { patients undergoing FET } \\
\text { cycles } \\
\text { Women: } \\
\text { - Total: } 80 \\
\text { - Treatment } 40 \\
\text { - Control } 40\end{array}$ & $\begin{array}{l}\text { - an antecedent of poor } \\
\text { endometrial response } \\
\text { - high-grade embryos } \\
\text { - Age < } 40 \text { years } \\
\text { - No history of endocrine } \\
\text { diseases } \\
\text {-No hysteroscopic surgeries. }\end{array}$ & $\begin{array}{l}\text { - estradiol by a step-up method } \\
\text { while in menstruation } \\
-3 \text { days high-grade embryos } \\
\text { transferred } \\
\text { - Luteal phase support with } \\
\text { progesterone (100 mg IM daily) } \\
\text {-E2 and P4 were measured in } \\
\text { an hour after first P4 injection }\end{array}$ & $\begin{array}{l}\text { Treatment group: } \\
\text { - Treatment: Sildenafil vaginal, } 50 \mathrm{mg} / \text { day } \\
\text { - Timing: during endometrial preparation } \\
\text { until the start P4 administration } \\
\text { Control group: } \\
\text { no intervention }\end{array}$ & $\begin{array}{l}\text { In Sildenafil treated group: } \\
\text { - Significant improvement of } \\
\text { endometrial thickness and } \\
\text { pattern } \\
\text { - Significantly higher chemical } \\
\text { pregnancy rate }\end{array}$ \\
\hline
\end{tabular}


Table 2. Cont.

\begin{tabular}{|c|c|c|c|c|c|c|}
\hline Author and Year & $\begin{array}{l}\text { Study Design and Time of } \\
\text { Realization }\end{array}$ & $\begin{array}{c}\text { Participants and Main } \\
\text { Inclusion Criteria (Number) }\end{array}$ & Enrollment Criteria & $\begin{array}{l}\text { Controlled Ovarian } \\
\text { Stimulation Protocols }\end{array}$ & Intervention Group & Main Finding \\
\hline $\begin{array}{l}\text { Check, J.H. et al., } \\
2004\end{array}$ & $\begin{array}{l}\text { Type: Single-center RCT } \\
\text { - Randomization: random } \\
\text { numbers table } \\
\text { - Blinding: not reported }\end{array}$ & $\begin{array}{l}20 \text { patients undergoing FET } \\
\text { cycles } \\
\text { Intention to treat: } \\
\text { - Total: } 20 \\
\text { - Treatment } 10 \\
\text { - Control } 10 \\
\text { Per protocol: } \\
\text { - Total: } 16 \\
\text { - Treatment } 9 \\
\text { - Control } 7\end{array}$ & $\begin{array}{l}\text { - failed to attain an } 8 \mathrm{~mm} \\
\text { endometrial thickness with oral } \\
\text { E2 }\end{array}$ & $\begin{array}{l}\text { - E2 oral regimen } \\
\text { Step up method: } \mathrm{E} 2 \\
2 \mathrm{mg} \times 5 \text { days, } 4 \mathrm{mg} \times 4 \text { days, } \\
6 \mathrm{mg} \times 5 \text { days } \\
\text { - Luteal phase support with } \\
\text { progesterone: } 200 \mathrm{mg} \text { twice } \\
\text { daily vaginal suppositories and } \\
100 \mathrm{mg} \text { in oil daily }\end{array}$ & $\begin{array}{l}\text { Treatment group: } \\
\text { - Treatment: Sildenafil vaginal, } 100 \mathrm{mg} / \text { day } \\
\text { - Timing: from day } 3 \text { to day } 9 \text { of endometrial } \\
\text { preparation } \\
\text { Control group: } \\
\text { Vaginal E2 } 2 \mathrm{mg} 2 \times \text { per day } \\
\text { Timing: from day } 2 \text { to peak thickness }\end{array}$ & No significant beneficial effects \\
\hline
\end{tabular}




\subsection{TI/IUI Section}

\subsubsection{Included Studies}

Six RCTs have been included in the TI/IUI section with a total of 460 participants (Table 1). Four studies $[37,38,40,41]$ did not report random sequence generation; one study [39] used simple randomization; one study [19] used computer number generation by the closed envelope method for randomization. All those studied did not report blindness of participants and personnel. Two studies were placebo-controlled [19,37]; in one study, the control group received co-intervention with estradiol [38], and the remaining were treatment versus no treatment [39-41]. All six studies assessed endometrial thickness by ultrasound on day 13 or 14 of the cycle or on the hCG trigger day. Three trials $[38,39,41]$ assessed CPR, and the other three trials $[19,37,40]$ evaluated ChPR. Two studies $[38,40]$ assessed the pregnancy rate on cumulative cycles (three).

\subsubsection{Patients}

Inclusion criteria were different among studies. Three studies enrolled women with unexplained fertility, with ovulatory cycles $[19,37,40]$. One study considered women affected by polycystic ovarian syndrome [39]. Two studies only considered infertile women with a persistently thin endometrium, defined as endometrium thickness $<7 \mathrm{~mm}$ on the 8th day of the cycle or on the day of ovulation trigger [38,41]. Four studies used clomiphene citrate at different dosages (50-150 mg) for 5 days during the menstrual cycle $[19,37,40,41]$. Mangal S. et Mahirishi S. [38] used both clomiphene citrate and gonadotropins for follicle recruitment and instead Mohamed T.Y. used letrozole [39]. In all studies, ovulation induction was performed with human chorionic gonadotropin. Only one study [19] described the luteal phase support with oral progesterone from the day of ovulation (Dufaston $10 \mathrm{mg}$ twice daily). When considering outcomes, in two studies $[38,40]$ authors calculated the cumulative pregnancy rate in three cycles.

\subsubsection{Type, Dose and Duration of Intervention}

In all except one trial [38], Sildenafil was orally administered. The daily dose of Sildenafil varied among studies; $25 \mathrm{mg}$ daily orally [41], $50 \mathrm{mg}$ daily orally [39,40] or $75 \mathrm{mg}$ daily orally [19,37] and $100 \mathrm{mg} /$ day vaginally [38]. The timing of administration was from the 7th and 8th days until ovulation induction in four trials [37-40], and just in two studies, the administration started from the beginning of the menstrual cycle (1st-2nd day) [19,41].

\subsection{IVF Fresh-ET/Frozen-ET Section}

\subsubsection{Included Studies}

Six RCTs have been included in the IVF Fresh-ET/Frozen-ET section (Table 2) with a total of 393 participants. Three RCTs reported data about COS with fresh embryo transfer with 198 patients included [42,45,46], and three RCTs reported data about FET with 195 patients included [12,43,44].

One study [46] did not report random sequence generation, and in three studies $[12,43,45]$, an adequate method of random sequence generation was used, and the randomizing methods of last two studies $[42,44]$ were judged at high risk of bias. Two studies $[42,45]$ were double blinded, and four studies $[12,43,44,46]$ did not report the blindness of participants and personnel. Two studies were placebo-controlled [42,45]; three [12,44,46] were treatment versus no treatment, and the remaining study [43] was vaginal Sildenafil vs. vaginal estradiol.

All six studies assessed endometrial thickness on the hCG trigger day or before progesterone administration starting. One trial [43] outcome was only endometrial thickness. Regarding the pregnancy rate, one study [12] evaluated ChPR, whereas the other three $[42,45,46]$ assessed CPR, and another one [44] considered both ChPR and CPR. 


\subsubsection{Patients}

Concerning COS and fresh ET, the inclusion criteria were different among trials. One study [46] enrolled infertile women with at least two previous failed FIVET cycles. Another study [45] considered women with at least two previous failed FIVET cycles and also a persistent thin endometrium defined as endometrial thickness $<7 \mathrm{~mm}$ measured the day of ovulation triggering. Moreover, in the latter study, enrolled women needed to have an adequate ovarian reserve defined as AMH $>1.5 \mathrm{ng} / \mathrm{mL}$ and $\mathrm{FSH}<10 \mathrm{UI} / \mathrm{mL}$. One trial [42] enrolled poor responders women with age $\leq 35$ and no previous ovarian surgery.

Concerning studies analyzing FET, all included patients reported an antecedent of a poor endometrial response during the previous cycle for frozen-thawed embryo transfer $[12,43,44]$. In all three studies, artificial cycles were used for endometrial preparation. Estradiol was administered by a step-up method in two studies [12,43]; instead, in one study [44], oral estradiol was administered in a fixed dose (2 mg every 6-8 h) from day 2 of the menstrual cycle.

\subsubsection{COS Cycles}

Considering only trials that evaluated fresh-ET, two studies $[45,46]$ evaluated women undergoing a long GnRH-agonist protocol with a starting dose of gonadotropins defined according to women characteristics, while in one trial [42], a short-antagonist protocol with a high starting dose of gonadotropins was employed. In all trials $[42,45]$ except one (in which data were not specified [46]), embryo transfer was performed after two-three days of an in vitro culture. Concerning luteal phase support (LPS), in one trial, a daily intramuscular injection of progesterone $(150 \mathrm{mg})$ was administered [42]; instead, in another study, LPS was indistinctly supported through the daily intramuscular or vaginal administration of progesterone [45]. Finally, the remaining trial did not specify the type of LPS [46].

\subsubsection{Type, Dose and Duration of Intervention}

Considering only trials that evaluated fresh-ET, in all except one trial (using oral Sildenafil, $50 \mathrm{mg}$ [42]), Sildenafil was vaginally administered [45,46]. The daily dose of vaginal Sildenafil was $100 \mathrm{mg} /$ day in both studies. The timing of administration was from the 1st-2nd day until an ovulation trigger or oocyte retrieval all trials $[42,45,46]$. In one of these three trials [45], one of the three randomized arms received a placebo from the from 1st-2nd day until 2 days before hCG administration, then Sildenafil until OPU.

Concerning studies analyzing FET, in all trials [12,43,44], Sildenafil was vaginally administered. The daily dose of Sildenafil varied among studies; two trials administered $100 \mathrm{mg} /$ day [43,44], one trial $50 \mathrm{mg} /$ day [12]. The timing of administration was from the beginning of the menstrual cycle (2nd-3rd day) until approximately the start of progesterone administration $[12,43,44]$.

\subsection{Risk of Bias}

Random sequence generation: four studies $[12,19,43,45]$ were judged at low risk of bias because an adequate method of random sequence generation was reported. Five studies were judged at unclear risk of bias (no information reported) $[37,38,40,41,46]$, and three trials were judged at high risk of bias because simple randomization was used $[39,42,44]$.

Allocation concealment: two studies were judged at low risk of bias [19,37]; one trial was judged at high risk of bias [42], while no information was reported in other studies [12,38-41,43-46].

Blinding of participants and personnel: two studies were at low risk of bias [42,45]; all other trials were at unclear risk because no information was reported [12,19,37-41,43,44,46].

Blinding of outcome assessment: in all studies, the blinding of the assessor was not specified. Because of the objective outcome, assessor knowledge could hardly interfere with the results, and studies were judged at low risk [12,19,37-46]. 
Incomplete outcome data: all studies were judged at high risk of bias because none of them reported data about the live birth rate and ongoing pregnancy rate $[12,19,37-46]$.

Selective data reporting: five studies were judged at high risk of selective data reporting due to the absence of the registered study protocol [37-44,46]. The remaining studies were judged at low risk [12,19]. For one study [45], there was inconsistency between the planned study start (recorded protocol) and the effective study start.

Other bias: in all studies, a power analysis was missing [12,19,37-46], and in one study [45], there was inconsistency between the population characteristic and inclusion criteria.

\subsection{Adverse Effects}

No trial reported adverse effects resulting from the intervention.

\subsection{Effects of Intervention (TI/IUI Section)}

Concerning ETh, the analysis included a total number of 360 participants from altogether five studies $[19,37,39-41]$, all analyzing TI. The only study analyzing IUI did not report this outcome [38]. Women receiving Sildenafil therapy showed higher ETh in comparison to controls, MD $1.39(95 \%$ CI $0.50-2.28, p=0.002)$, but with high statistical heterogeneity (I2 $=86 \%$ ). See Figure 2a.

Concerning CPR, three papers reported this outcome [38,39,41], one analyzing IUI [38] and two TI $[39,41]$. We found a significant advantage related to Sildenafil treatment with a total RR of 1.79 (95\% CI 1.09-2.95, $p=0.02$ ) with no heterogeneity (I2 $=0 \%)$. The separate analysis of TI and IUI showed no statistical significance. See Figure $2 \mathrm{~b}$.

Concerning ChPR, six papers reported this outcome [19,37-41], one analyzing IUI [38] and five TI $[19,37,39-41]$. We found a significant advantage related to Sildenafil treatment with a total RR of $1.64(95 \%$ CI 1.26-2.12, $p=0.0002)$, with no statistical heterogeneity (I2 $=0 \%$ ). Considering only TI, the RR was 1.66 (95\% CI 1.26-2.17, $p=0.0002$ ), but no significant advantages were found in the paper reporting data from IUI cycles. See Figure 2c.

Subgroups analysis:

Concerning administration route (vaginal vs. oral), five papers [19,37,39-41] reported data from oral administration and only one paper from vaginal [38]. As the only study evaluating vaginal administration in this subgroup (TI/IUI) [38] compared Sildenafil to estrogen, while the other subgroup studies compared Sildenafil to no intervention, we excluded this study for this analysis.

Concerning the timing of Sildenafil administration (at the beginning of stimulation versus delayed start) and ETh, three papers reported data about delayed start $[37,39,40]$ and two papers about the beginning of stimulation $[19,41]$. Significant beneficial effects in terms of ETh seemed related to delayed start (MD 1.70, 95\% CI 0.36-3.03, I2 = 90\%, $p=0.01$ ); on the contrary, administering Sildenafil at the beginning of the stimulation seems not effective (MD 0.94, 95\% CI -0.11-1.99, I2 = 69\%, $p=0.08$ ). See Supplemental Figure S1a.

Concerning the timing of Sildenafil administration (at the beginning of stimulation versus delayed start) and ChPR, four papers reported data about delayed start [37-40] and two papers about the beginning of stimulation $[19,41]$. ChPR results were significantly higher with delayed start [37-40] (RR 1.65, 95\% CI 1.24-2.20, I2 =0\%, $p=0.0006$ ). On the contrary, there was not a significant ChPR increase when Sildenafil administration starts at the beginning of stimulation $[19,41]$ (RR $1.57,95 \%$ CI $0.87-2.83$ I2 $=0 \%, p=0.13$ ). See Supplemental Figure S1b. 


\section{a - Endometrial Thickness}

\begin{tabular}{|c|c|c|c|c|c|c|c|c|c|}
\hline \multirow{2}{*}{ Study or Subgroup } & \multicolumn{3}{|c|}{ SIDENAFIL } & \multicolumn{3}{|c|}{ CONTROL } & \multicolumn{2}{|r|}{ Mean Difference } & \multirow{2}{*}{$\begin{array}{c}\text { Mean Difference } \\
\text { IV, Random, } 95 \% \mathrm{Cl}\end{array}$} \\
\hline & Mean & SD & Total & Mean & $\mathrm{SD}$ & Total & Weight & IV, Random, $95 \% \mathrm{Cl}$ Year & \\
\hline TIMED INTERCOURSE & & & & & & & & & \\
\hline Fahmy AA et al 2015 & 10.36 & 1.4 & 35 & 9.41 & 1.74 & 35 & $20.3 \%$ & $0.95[0.21,1.69] 2015$ & $\rightarrow$ \\
\hline Reddy LP et al 2016 & 9.64 & 1.8 & 40 & 8.47 & 2.3 & 40 & $19.0 \%$ & $1.17[0.26,2.08] 2016$ & 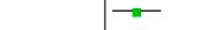 \\
\hline Kortam MAMF et al 2018 & 9.8 & 1.7 & 45 & 8.4 & 1.2 & 45 & $21.3 \%$ & $1.40[0.79,2.01] 2018$ & - \\
\hline Vardhan S et al 2019 & 9.38 & 2 & 40 & 9.06 & 2.6 & 40 & $18.1 \%$ & $0.32[-0.70,1.34] 2019$ & $=$ \\
\hline Mohamed TY. 2019 & 12.7 & 0.8 & 20 & 9.8 & 1.1 & 20 & $21.4 \%$ & $2.90[2.30,3.50] 2019$ & $\pi$ \\
\hline Total $(95 \% \mathrm{Cl})$ & & & 180 & & & 180 & $100.0 \%$ & $1.39[0.50,2.28]$ & \\
\hline $\begin{array}{l}\text { Heterogeneity: } \text { Tau }^{2}=0.87 \\
\text { Test for overall effect: } Z=\end{array}$ & $\begin{array}{l}\mathrm{Chi}^{2}=2 \\
06(\mathrm{P}=\end{array}$ & $\begin{array}{l}8.60 \\
0.002\end{array}$ & $\mathrm{df}=4$ & $(P<0.0$ & 0001); & $I^{2}=86$ & & & $\begin{array}{ccccc}4 & -2 & 1 & 2 & 4 \\
\text { CONTROL } & \text { SIDENAFIL }\end{array}$ \\
\hline
\end{tabular}

\section{b - Clinical Pregnancy Rate}

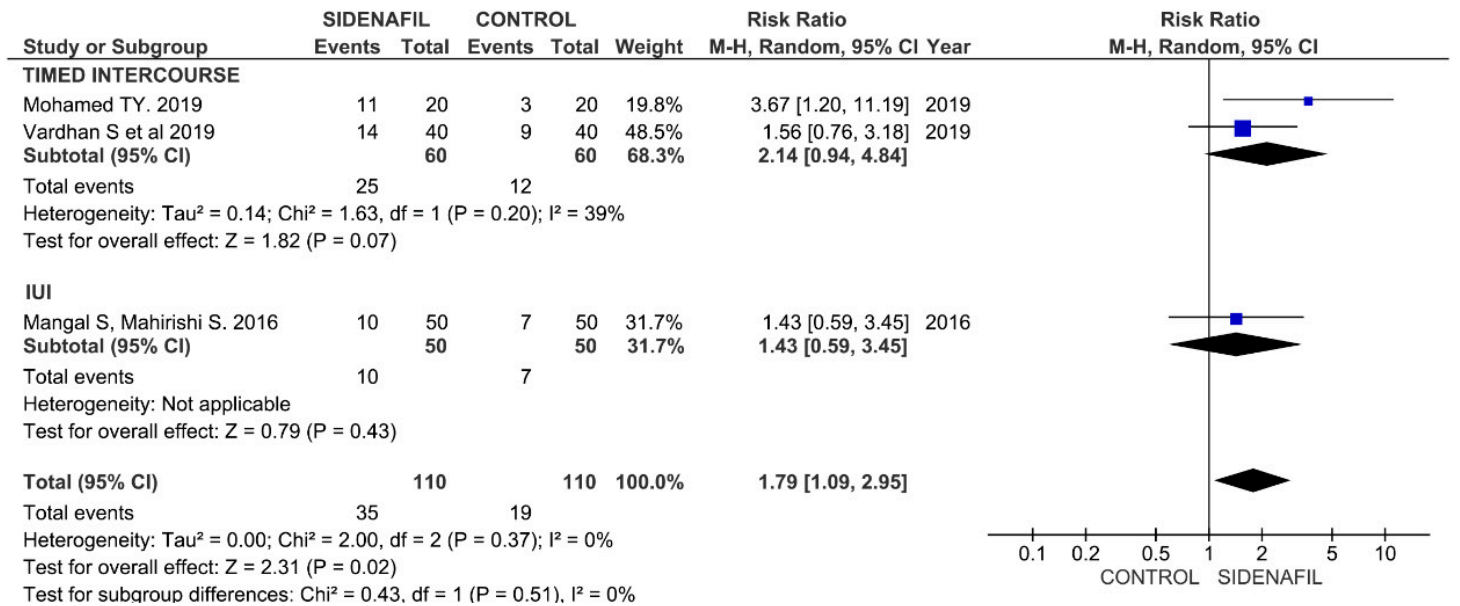

\section{c - Chemical Pregnancy Rate}

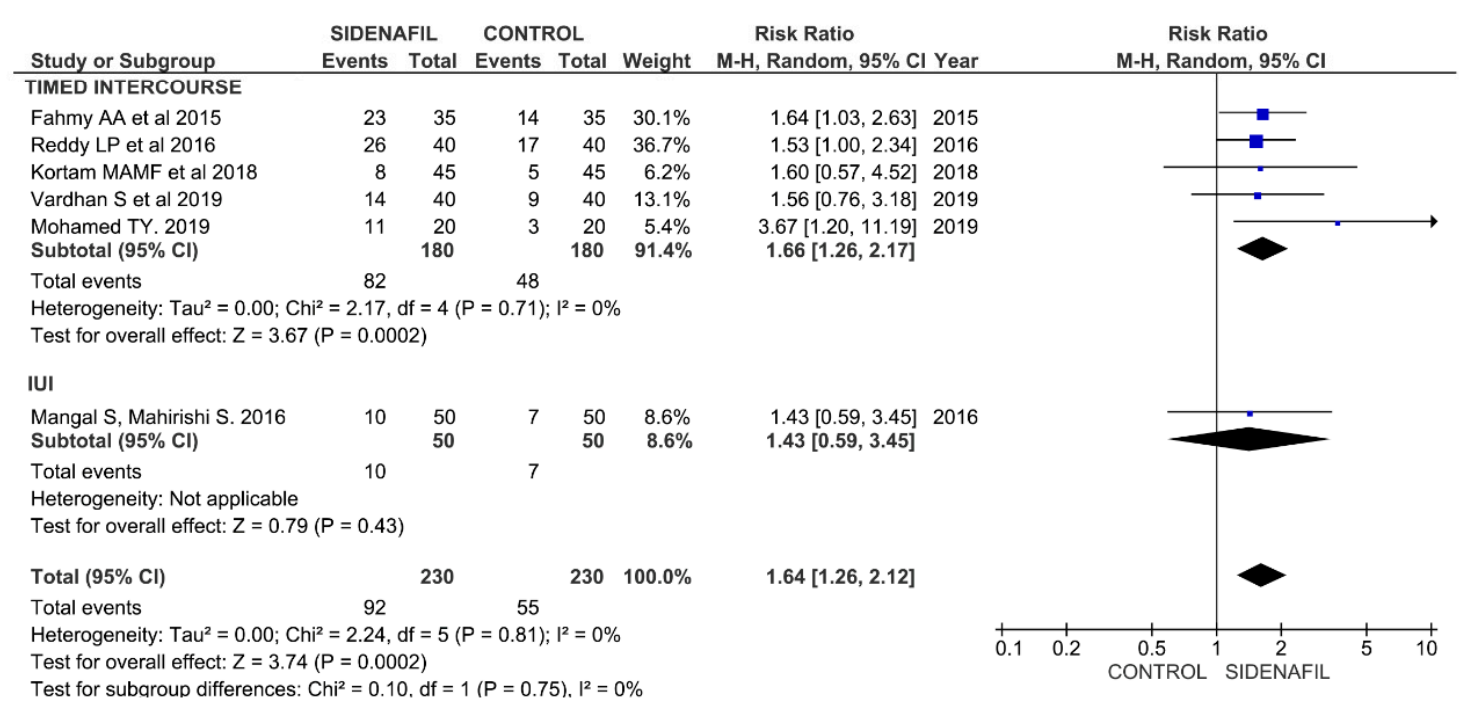

Figure 2. (a) Forest plot of comparison: endometrial thickness (ETh) according to group allocation-intervention (Sildenafil) versus control in intrauterine insemination and timed intercourse cycles. (b) Forest plot of comparison: clinical pregnancy rate (CPR) according to group allocation-intervention (Sildenafil) versus control in intrauterine insemination and timed intercourse cycles. (c) Forest plot of comparison: chemical pregnancy rate (ChPR) according to group allocation-intervention (Sildenafil) versus control in intrauterine insemination and timed intercourse cycles. 


\subsection{Effects of Intervention (IVF Fresh-ET/Frozen-ET Section)}

Concerning ETh, five papers reported this outcome [42-46], three of them reported data from IVF fresh-ET (IVF group) [42,45,46] and two from frozen-ET (FET group) [43,44], with a total of 313 participants. Considering together fresh- and frozen-ET, we did not find a significant advantage in the intervention group in comparison to controls (MD 0.82, $95 \%$ CI $-0.19-1.82, p=0.11)$. When we evaluated separately the two groups, a significant advantage in the intervention group in comparison to controls was absent both in the IVF group (MD 1.25, 95\% CI $-0.44-2.94, p=0.15$ ) and in the FET group (MD 0.22, 95\% CI $-1.67-2.10, p=0.82)$. See Figure $3 a$.

Concerning CPR, four papers reported this outcome [42,44-46], three of them reported data from IVF fresh-ET (IVF group) [42,45,46] and only one from frozen-ET (FET group) [44], with a total of 293 participants. We found no significant increase in the CPR in the intervention group compared to controls analyzing together (RR 1.45, 95\% CI 0.93-2.25) and separately by IVF and FET group. In particular, a significant advantage in the intervention group in comparison to controls was absent in the IVF group (RR 1.31, 95\% CI 0.76-2.26) and in the FET group (RR 1.75, 95\% CI 0.82-3.76). See Figure 3b.

Concerning ChPR, analyzing together IVF fresh-ET and frozen-ET, we found a significantly higher ChPR in the intervention group compared to controls (RR 1.47, 95\% CI $1.0-2.13, p=0.05)$, with no heterogeneity $(\mathrm{I} 2=0 \%)$. A separate analysis was not significant. We found no significant increase in the ChPR neither in the intervention group of women who underwent IVF cycles compared to controls (RR 1.30, 95\% CI 0.75-2.22, $p=0.89$ ) nor in the intervention group of women who underwent FET cycles compared to controls (RR $1.65,95 \%$ CI 0.98-2.78, $p=0.96)$. See Figure 3c.

Subgroup analysis:

Concerning administration route (vaginal vs. oral) and ETh, we found no significant effect of Sildenafil on endometrial thickness (MD 0.33, 95\% CI $-0.54-1.20, p=0.45$ ), but heterogeneity was high $(\mathrm{I} 2=95 \%)$. See Supplemental Figure S2a.

Concerning administration route (vaginal vs. oral) and ChPR, a significant increase in the ChPR was found from vaginal administration, with a RR of $1.49,(95 \%$ CI 1.00-2.21, $p=0.05)$. No significant benefits in terms of ChPR seem to be associated to oral administration, even if only one study was included in this section [13]. See Supplemental Figure S2b.

\section{a - Endometrial Thickness}

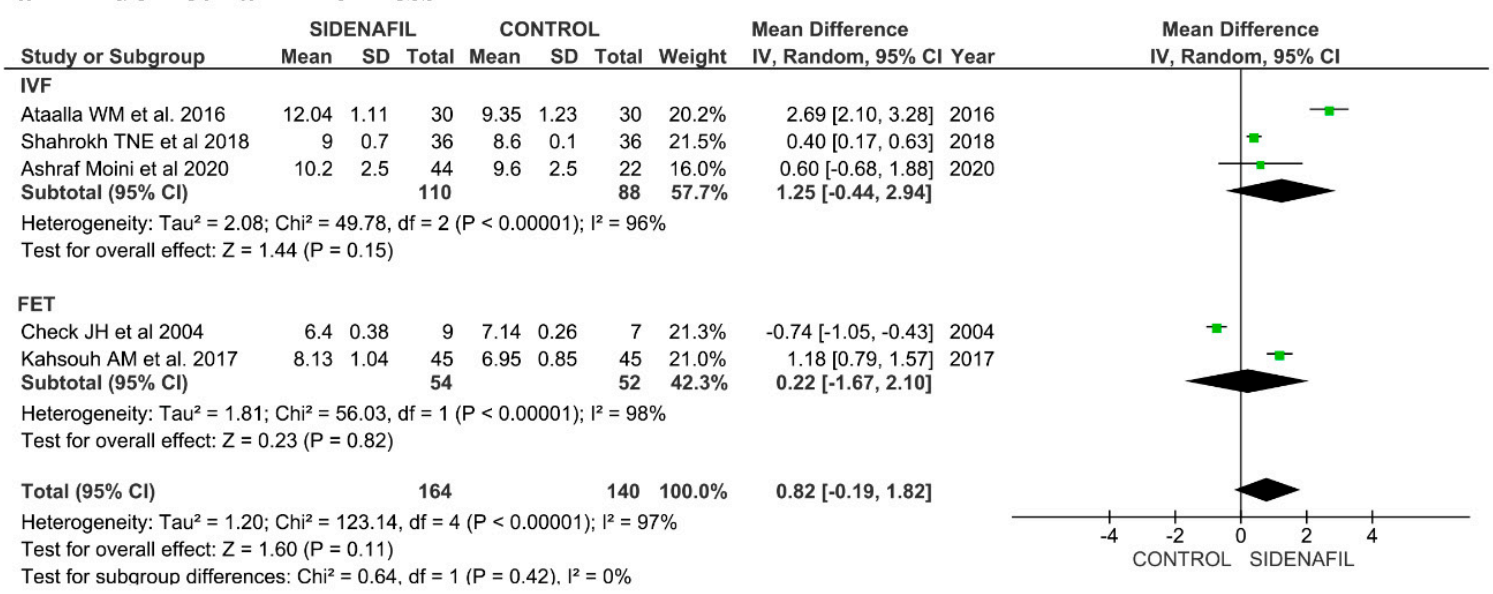

Figure 3. Cont. 


\section{b - Clinical Pregnancy Rate}

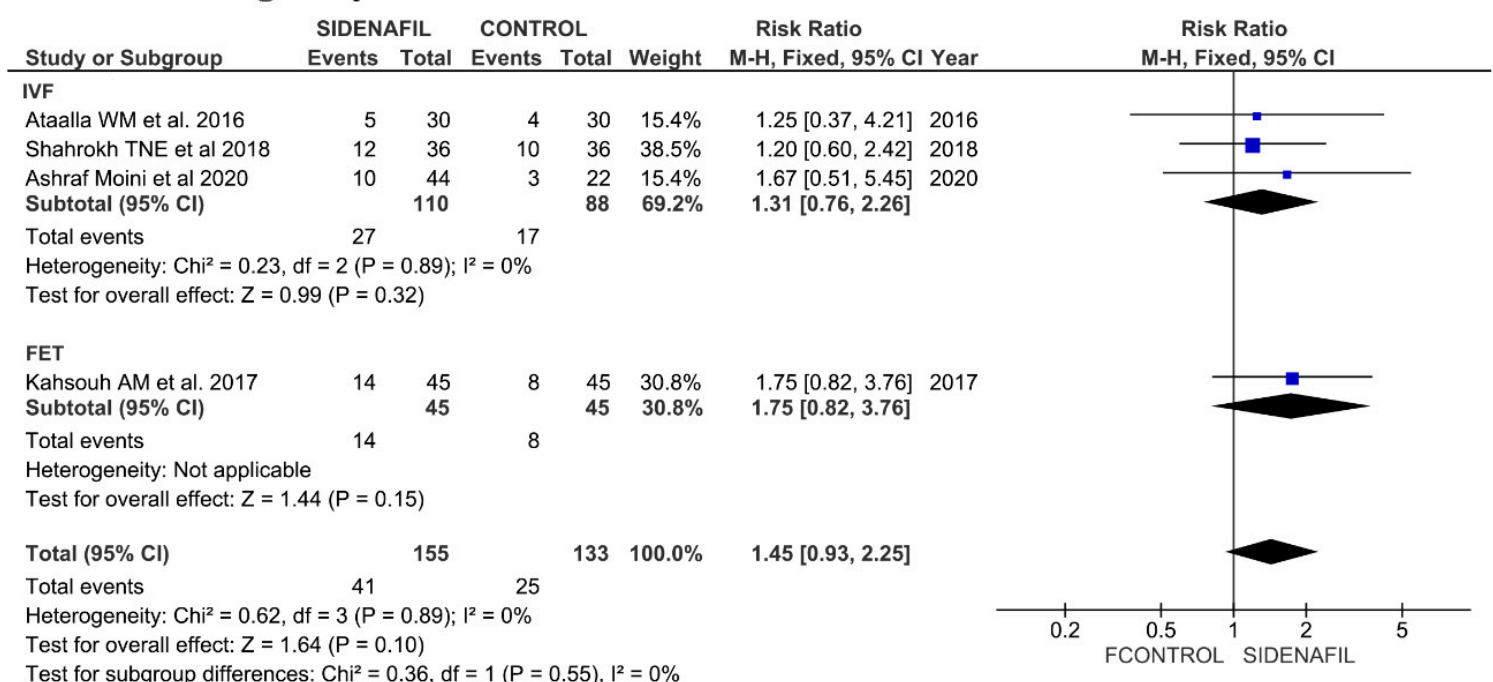

\section{c - Chemical Pregnancy Rate}

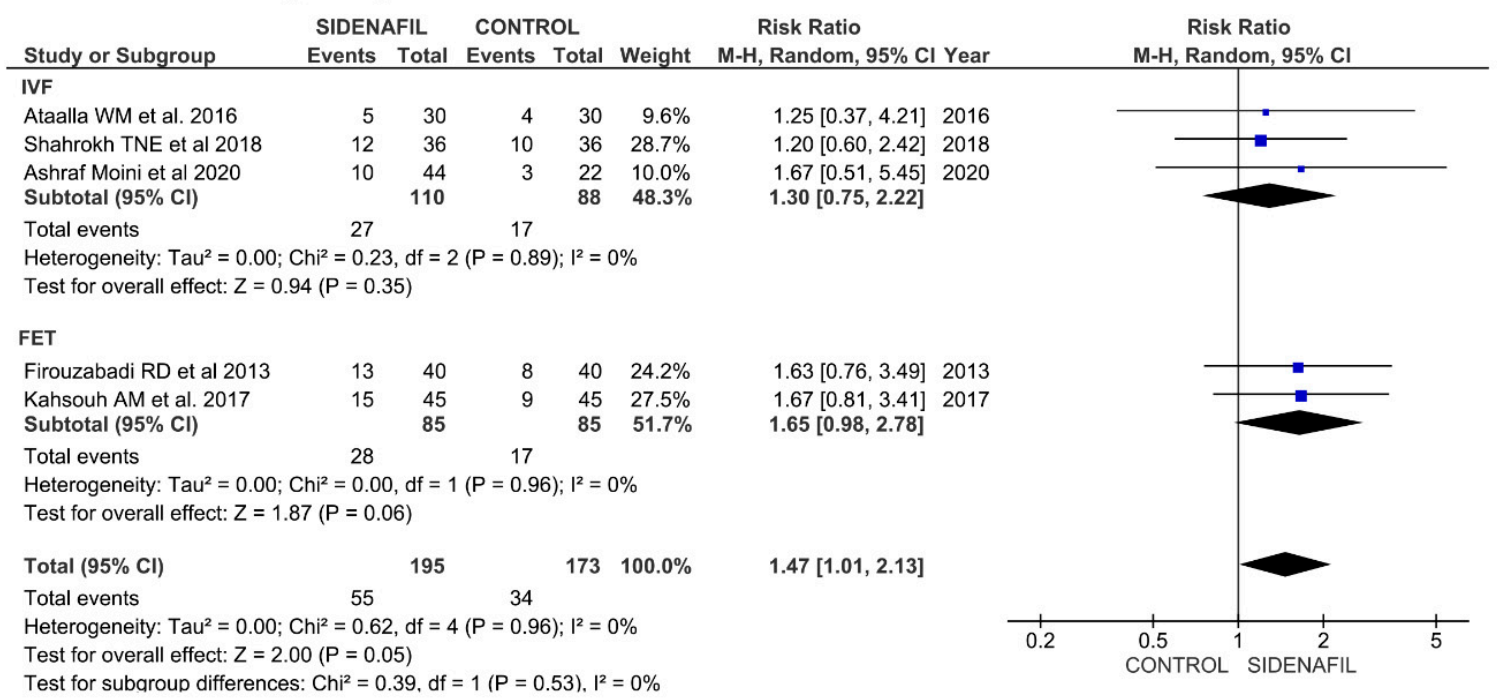

Figure 3. (a) Forest plot of comparison: endometrial thickness (ETh) according to group allocation-intervention (Sildenafil) versus control in IVF fresh and frozen embryo transfer. (b) Forest plot of comparison: clinical pregnancy rate (CPR) according to group allocation-intervention (Sildenafil) versus control in IVF fresh and frozen embryo transfer. (c) Forest plot of comparison: chemical pregnancy rate (ChPR) according to group allocation-intervention (Sildenafil) versus control in IVF fresh and frozen embryo transfer.

\section{Discussion}

\subsection{General Considerations}

Despite the improvement in ARTs, the live birth rate is still low even if top-quality embryos are obtained [47]. A great issue is the obtaining of a receptive endometrium [48,49]. Despite new technologies that allow the detection of the implantation window through an endometrial biopsy performed during the previous menstrual cycle [50,51], the widely used method in the clinical practice to establish if an endometrium is suitable for implantation is the transvaginal ultrasound evaluation of ETh [52-54].

The underlying cause of the thin endometrium must be sought and resolved before attempting another cycle for achieving pregnancy. Hysteroscopy is usually the gold standard as a second-line diagnostic investigation [55-57], and Asherman's syndrome is the first pathological condition that must be excluded [58]. Another underlying underdiagnosed 
condition that has recently been re-examined might be chronic endometritis that can be suspected with diagnostic hysteroscopy and confirmed with endometrial biopsy [59-62].

Despite these second-line investigations, many times the underlying cause cannot be identified. Although sometimes the endometrium might be receptive even if a thinner value is used as a cut-off [49], an association has been demonstrated between low endometrial thickness, ART failure and adverse pregnancy outcomes related to an abnormal placentation such as hypertension, preeclampsia, intrauterine growth defects [63-65].

For these reasons, many efforts have been made in order to obtain a thicker endometrium with different strategies involving hormonal approaches (estradiol administration adjustment, hCG administration during the follicular phase, GnRH agonist administration during the luteal phase), the intrauterine infusion of growth factors such as the granulocyte colony-stimulating factor and platelet-rich plasma and the usage of factors that act on endometrium vascularity [66]. For this latter approach, low dose aspirin has been used and also phosphodiesterase inhibitors [66]. Among phosphodiesterase inhibitors, there are non-specific inhibitors such as pentoxifylline and selective ones such as phosphodiesterase type 5 inhibitor (Tadalafil and Sildenafil) [24,67]. However, despite different approaches that might be available, a lack of solid evidence in the published literature limits their clinical applicability.

In particular, the usage of selective phosphodiesterase type 5 inhibitors seems a promising strategy supported by a valid biological rationale. Indeed, Sildenafil causes vasodilatation preventing cGMP breakdown and increasing relaxation of the smooth muscle [12,45]. This effect is widely used in males for erectile dysfunction [68]. With a similar mechanism, Sildenafil might increase uterine artery flow with subsequent enhanced endometrial vascularization and improved endometrial growth under estrogenic influence $[19,45]$.

\subsection{Main Findings}

In this meta-analysis, we tested the effect of Sildenafil as an add-therapy during the TI or IUI cycle and during IVF and fresh-ET or frozen-ET on ETh and the pregnancy rate. We found that Sildenafil supplementation significantly improves ETh when administered during a timed intercourse or IUI cycles; on the contrary, it does not seem to take a significant advantage when administered during fresh-ET or frozen-ET. In both groups, there was a bad consistency (I2 86\% and 97\%, respectively). Similarly, analyzing TI or IUI cycles, we found that the intervention was associated with a higher CPR and ChPR (low inconsistency, I2 $=0 \%$ ). In fresh-ET or frozen-ET groups, there was a higher rate of ChPR in Sildenafil co-treatment women.

A subgroup analysis for the evaluation of the way of Sildenafil administration was possible only for the IVF Fresh-ET/Frozen-ET groups. Even if only one study evaluated the oral administration of Sildenafil in these groups [42], vaginal administration seems to be more effective, but further studies are needed to confirm these results.

A subgroup analysis revealed that also timing of administration had a significant effect. In fact, only the delayed starting of Sildenafil administration during the TI and IUI cycles led to a thicker endometrium and to a higher biochemical pregnancy rate.

\subsection{Interpretation}

Based on our results, it would seem that ETh, CPR and ChPR are higher with the use of Sildenafil in women undergoing TI and IUI. In particular, a subgroup analysis evidenced that the delayed start of Sildenafil administration might significantly increase the chances of obtaining a thicker endometrium and pregnancy. Further studies are needed to reveal whether the way of Sildenafil administration has a significant effect on endometrial thickness and the pregnancy rate.

Considering women undergoing TI/IUI [19,37,39-41], in all except one trial [38], Sildenafil was orally administered. In this group, a significant improvement was highlighted for Eth, CPR and ChPR. Vaginal administration did not show significant advantages. This 
way of administration was evaluated in a single trial [38], but this trial compared Sildenafil to estrogen, while the other subgroup studies compared Sildenafil to no intervention.

Regarding the improvement of Eth in women undergoing MAR treated with Sildenafil, it is known that this molecule improves artery blood flow through the prevention of cGMP breakdown [18]. This leads to an increase in smooth muscle relaxation and vasodilation. The possible explanation of the impact of the Sildenafil on the endometrium is that this molecule exerts a positive effect on endometrial growth increasing endometrial vascularization through the described method. This mechanism acts in synergy with estrogens that secrete angiogenic factors to enhance revascularization $[69,70]$. This improvement in endometrial growth through an increased vascularization led to an improvement in the CPR and ChPR.

Better outcomes in terms of the CPR and ChPR were reported when Sildenafil supplementation was started 7-8 days from ovarian stimulation.

Physiologically, endometrial vascularization increases during the endometrial proliferative phase that generally last from the 7th day of the menstrual cycle under the influence of estrogens through the action of different angiogenic factors [69-71]. As natural killer cells release cytokines that are involved in embryo implantation failure through nitric oxide action, it may be beneficial to limit Sildenafil administration only when spiral arteries have already formed to avoid a high concentration of nitric oxide [72]. In fact, if the assumption of Sildenafil administration is to increase the endometrial vascularity, the delayed administration of this molecule adapts better to the physiology of the endometrial cycle, acting in concert with the increase in estrogen.

Considering women undergoing fresh or frozen-ET [12,42-46], vaginal Sildenafil represented the most common way of administration, and only one trial administered oral Sildenafil [42]. In this group, a significant improvement in ETh was not highlighted in patients treated with Sildenafil. Nevertheless, in treated women, a higher pregnancy rate was present. The only trail that considered oral administration in women undergoing the described ART techniques [42] showed a significant improvement in ETh but not in the pregnancy rate. However, considering women undergoing fresh- or frozen-ET, only the ChPR improvement was reported and not the CPR.

Regarding the non-improvement of Eth in women undergoing ART treated with Sildenafil, different explanations can be provided for patients undergoing fresh-ET and for patients undergoing frozen-ET. Women undergoing controlled ovarian stimulation achieve an increase in peak serum estradiol levels up to 10-12 times higher [73]. Since estradiol acts on the growth of the endometrium, the maximum effect on endometrial thickness can be obtained with only the high concentration of estrogen due to ovarian stimulation.

Instead, all women evaluated in the frozen-ET groups underwent an endometrial preparation with an artificial cycle. The dynamics of action of the estrogens administered in the artificial cycles of endometrial preparation on the endometrium are not fully known. It is possible that in this type of treatment, the synergy is present in MAR treatments in which Sildenafil acts in concert with estrogen to increase endometrial vascularization and therefore increase its thickness is lost.

Improvement in the ChPR was reported when the fresh-ET and frozen-ET groups were analyzed together. However, there was no significant improvement when the two groups were analyzed separately. The lack of improvement in the analysis of the frozen-ET group alone may be due to the number of limited studies available. In frozen-ET, the supplementation of Sildenafil might be useful to reach the maximum effect on endometrial vascularization, while maybe this is not possible in women undergoing fresh-ET who have higher levels of estrogens. Further studies are necessary to prove this hypothesis.

In summary, a biological explanation of the apparently different efficacies of Sildenafil among women undergoing TI and IUI compared to women undergoing IVF and fresh or frozen-ET might lie on the different levels of estrogen that are achieved during the different types of treatments [74,75]. In fact, as previously reported, estrogen treatment is an option for achieving a thicker endometrium, and high levels of endogenous estradiol might act 
as a cotreatment. This aspect may explain the non-significant results in endometrium thickness obtained in women undergoing transfer after treatments that required higher estradiol levels. Moreover, in our meta-analysis, the pregnancy rate resulted higher in Sildenafil treated women $(p=0.05)$, probably due to higher vascularization and, therefore, higher receptivity.

Regarding the route of administration, further studies are needed to evaluate the efficacy of the vaginal route of administration of sildenafil in women undergoing ART. This route of administration could ensure a higher endometrial concentration of sildenafil. In fact, vaginal absorption occurs through the vaginal mucosa which is highly vascularized, and it does not depend on food intake and avoids hepatic metabolism.

\subsection{Strengths and Limitations}

The present meta-analysis is the only one available on this issue. However, outcomes were calculated by pooling the results of a small number of studies and a small number of patients. Moreover, a certain heterogeneity across studies was present in terms of inclusion criteria (exclusion of uterine pathologies), Sildenafil therapy (way, dose and timing of administration) and population characteristics.

\section{Conclusions}

While the data from this study support a positive impact of sildenafil on ETh and pregnancy rate in women undergoing timed intercourses, Sildenafil therapy does not appear to improve outcomes in women undergoing IUI and IVF treatments. In fact, available data support a positive impact of Sildenafil on ETh and the pregnancy rate only in women undergoing timed intercourses, specifically when it is administered after day 7 of the cycle. Understanding endometrial angiogenesis mechanisms and the roles of angiogenic factors during ART treatments might provide new insights and clarify the effect of Sildenafil on the endometrium during different phases of the endometrial cycle. Due to the limitations of available studies, further RCTs are still mandatory in order finally to confirm or not the real clinical effectiveness as well as to establish the best timing, dose and duration of Sildenafil administration.

Supplementary Materials: The following are available online at https:/ /www.mdpi.com/article/10 $.3390 /$ jcm10194346/s1, Figure S1: a Forest plot of comparison, subgroup analysis according to time of administration: endometrial thickness (ETh) according to group allocation-intervention (Sildenafil) versus control in insemination and timed intercourse cycles. b Forest plot of comparison, subgroup analysis according to time of administration: chemical pregnancy rate (ChPR) according to group allocation-intervention (Sildenafil) versus control in intrauterine insemination and timed intercourse cycles. Figure S2: a Forest plot of comparison, subgroup analysis according to administration route: endometrial thickness (ETh) according to group allocation-intervention (Sildenafil) versus control in IVF fresh and frozen embryo transfer. $b$ Forest plot of comparison, subgroup analysis according to administration route: chemical pregnancy rate (ChPR) according to group allocation-intervention (Sildenafil) versus control in IVF fresh and frozen embryo transfer.

Author Contributions: L.M., A.V., A.A., G.A. conceptualized the study; L.M., M.N. and F.D. extracted the data; M.N. and G.C. performed the statistical analysis; L.M., M.N., A.A. and L.B. performed the data interpretation and prepared figures; L.M., M.N. wrote the manuscript; G.C. and G.A. reviewed the manuscript. All authors have read and agreed to the published version of the manuscript.

Funding: This study had no funding and no financial support.

Data Availability Statement: The datasets used and/or analyzed during the current study are available from the corresponding author on reasonable request.

Conflicts of Interest: The authors declare no conflict of interest. 


\section{References}

1. The European IVF-Monitoring Consortium (EIM) for the European Society of Human Reproduction and Embryology (ESHRE); Embryology; Wyns, C.; De Geyter, C.; Calhaz-Jorge, C.; Kupka, M.S.; Motrenko, T.; Smeenk, J.; Bergh, C.; Tandler-Schneider, A.; et al. ART in Europe, 2017: Results generated from European registries by ESHRE ${ }^{\dagger}$. Hum. Reprod. Open 2021, 2021, hoab026. [PubMed]

2. Zhang, T.; Li, Z.; Ren, X.; Huang, B.; Zhu, G.; Yang, W.; Jin, L. Endometrial thickness as a predictor of the reproductive outcomes in fresh and frozen embryo transfer cycles: A retrospective cohort study of 1512 IVF cycles with morphologically good-quality blastocyst. Med. Baltim. 2018, 97, e9689. [CrossRef] [PubMed]

3. Blesa, D.; Ruiz-Alonso, M.; Simon, C. Clinical management of endometrial receptivity. Semin. Reprod. Med. 2014, 32, 410-413. [CrossRef]

4. Liu, Y.; Ye, X.Y.; Chan, C. The association between endometrial thickness and pregnancy outcome in gonadotropin-stimulated intrauterine insemination cycles. Reprod. Biol. Endocrinol. 2019, 17, 14. [CrossRef]

5. Liu, X.; Qu, P.; Bai, H.; Shi, W.; Shi, J. Endometrial thickness as a predictor of ectopic pregnancy in 1125 in vitro fertilization-embryo transfer cycles: A matched case-control study. Arch. Gynecol. Obstet. 2019, 300, 1797-1803. [CrossRef]

6. Groenewoud, E.R.; Cohlen, B.J.; Al-Oraiby, A.; Brinkhuis, E.A.; Broekmans, F.J.M.; de Bruin, J.P.; van Dool, G.; Fleisher, K.; Friederich, J.; Goddijn, M.; et al. Influence of endometrial thickness on pregnancy rates in modified natural cycle frozen-thawed embryo transfer. Acta Obstet. Gynecol. Scand. 2018, 97, 808-815. [CrossRef]

7. Zolghadri, J.; Haghbin, H.; Dadras, N.; Behdin, S. Vagifem is superior to vaginal Premarin in induction of endometrial thickness in the frozen-thawed cycle patients with refractory endometria: A randomized clinical trial. Iran. J. Reprod. Med. 2014, 12, 415-420.

8. Noventa, M.; Vitagliano, A.; Andrisani, A.; Blaganje, M.; Viganò, P.; Papaelo, E.; Scioscia, M.; Cavallin, F.; Ambrosini, G.; Cozzolino, M. Testosterone therapy for women with poor ovarian response undergoing IVF: A meta-analysis of randomized controlled trials. J. Assist. Reprod. Genet. 2019, 36, 673-683. [CrossRef] [PubMed]

9. Davar, R.; Miraj, S.; Farid Mojtahedi, M. Effect of adding human chorionic gonadotropin to frozen thawed embryo transfer cycles with history of thin endometrium. Int. J. Reprod. Biomed. 2016, 14, 53-56. [CrossRef] [PubMed]

10. Qublan, H.; Amarin, Z.; Al-Qudah, M.; Diab, F.; Nawasreh, M.; Malkawi, S.; Balawneh, M. Luteal phase support with GnRH-a improves implantation and pregnancy rates in IVF cycles with endometrium of $<$ or $=7 \mathrm{~mm}$ on day of egg retrieval. Hum. Fertil. (Camb. Engl.) 2008, 11, 43-47.

11. Weckstein, L.N.; Jacobson, A.; Galen, D.; Hampton, K.; Hammel, J. Low-dose aspirin for oocyte donation recipients with a thin endometrium: Prospective, randomized study. Fertil. Steril. 1997, 68, 927-930. [CrossRef]

12. Firouzabadi, R.D.; Davar, R.; Hojjat, F.; Mahdavi, M. Effect of sildenafil citrate on endometrial preparation and outcome of frozen-thawed embryo transfer cycles: A randomized clinical trial. Iran. J. Reprod. Med. 2013, 11, 151-158.

13. Acharya, S.; Yasmin, E.; Balen, A.H. The use of a combination of pentoxifylline and tocopherol in women with a thin endometrium undergoing assisted conception therapies-A report of 20 cases. Hum. Fertil. (Camb. Engl.) 2009, 12, 198-203. [CrossRef]

14. Bodombossou-Djobo, M.M.; Zheng, C.; Chen, S.; Yang, D. Neuromuscular electrical stimulation and biofeedback therapy may improve endometrial growth for patients with thin endometrium during frozen-thawed embryo transfer: A preliminary report. Reprod. Biol. Endocrinol. 2011, 9, 122. [CrossRef]

15. Sarvi, F.; Arabahmadi, M.; Alleyassin, A.; Aghahosseini, M.; Ghasemi, M. Effect of increased endometrial thickness and implantation rate by granulocyte colony-stimulating factor on unresponsive thin endometrium in fresh in vitro fertilization cycles: A randomized clinical trial. Obstet. Gynecol. Int. 2017, 2017, 3596079. [CrossRef]

16. Kunicki, M.; Lukaszuk, K.; Liss, J.; Skowronska, P.; Szczyptanska, J. Granulocyte colony stimulating factor treatment of resistant thin endometrium in women with frozen-thawed blastocyst transfer. Syst. Biol. Reprod. Med. 2017, 63, 49-57. [CrossRef]

17. Wang, X.; Liu, L.; Mou, S.; Zhao, H.; Fang, J.; Xiang, Y.; Zhao, T.; Sha, T.; Ding, J.; Hao, C. Investigation of platelet-rich plasma in increasing proliferation and migration of endometrial mesenchymal stem cells and improving pregnancy outcome of patients with thin endometrium. J. Cell. Biochem. 2019, 120, 7403-7411. [CrossRef] [PubMed]

18. Scaglione, F.; Donde, S.; Hassan, T.A.; Jannini, E.A. Phosphodiesterase type 5 inhibitors for the treatment of erectile dysfunction: Pharmacology and clinical impact of the sildenafil citrate orodispersible tablet formulation. Clin. Ther. 2017, 39, 370-377. [CrossRef] [PubMed]

19. Kortam, M.F.; Mohammad, H.F.; Mobarak, M.H.; Bazazo, A.I. The effect of estradiol valerate with and without oral sildenafil on endometrial thickness and pregnancy rates in infertile women: A R.C.T. Evid. Based Womens Health J. 2018, 8, 5. [CrossRef]

20. Jerzak, M.; Kniotek, M.; Mrozek, J.; Gorski, A.; Baranowski, W. Sildenafil citrate decreased natural killer cell activity and enhanced chance of successful pregnancy in women with a history of recurrent miscarriage. Fertil. Steril. 2008, 90, 1848-1853. [CrossRef]

21. Forman, E.J.; Hong, K.H.; Ferry, K.M.; Tao, X.; Taylor, D.; Levy, B.; Treff, N.R.; Scott, R.T., Jr. In vitro fertilization with single euploid blastocyst transfer: A randomized controlled trial. Fertil. Steril. 2013, 100, 100-107.e101. [CrossRef] [PubMed]

22. Moher, D.; Liberati, A.; Tetzlaff, J.; Altman, D.G. Preferred reporting items for systematic reviews and meta-analyses: The PRISMA statement. PLoS Med. 2009, 6, e1000097. [CrossRef] [PubMed]

23. Ammar, I.M.M.; Salem, M.A.A. Effect of oral Tadalafil on endometrial thickness in patients receiving Clomiphene citrate for ovulation induction. Middle East Fertil. Soc. J. 2018, 23, 121-125. [CrossRef] 
24. Mendez Lozano, D.H.; Lenero, M.V.; Gonzalez, R.L.; Scheffer, J.B.; Gonzalez, M.T.; Barron, Y.; Frydman, R. Tadalafil for Endometrial Growth in Clomiphene Citrate stimulated cycles in an IUI programma: A pilot study. Facts Views Vis. ObGyn 2015, 7, 231-237.

25. Kim, K.R.; Lee, H.S.; Ryu, H.E.; Park, C.Y.; Min, S.H.; Park, C.; Jee, B.C. Efficacy of luteal supplementation of vaginal sildenafil and oral estrogen on pregnancy rate following IVF-ET in women with a history of thin endometria: A pilot study. Medicine 2010, 3, 155-158. [CrossRef]

26. Das, V.; Agarwal, A.; Pandey, A.; Jain, V.; Agarwal, S.; Ara, A. P793 Evaluation of role of sildenafil in improving IUI success rates. Int. J. Gynecol. Obstet. 2009, 107, S638. [CrossRef]

27. Chanona, J.; Garcia, M.; Ruvalcaba, L.; Bermudez, A.; Muniz, M.; Beltran, M.; Cuneo, S. The Mexican experience in the use of vaginal sildenafil in patients with poor endometrial response. Int. Congr. Ser. 2004, 1271, 19-21. [CrossRef]

28. Margreiter, M.; Weghofer, A.; Feichtinger, W. Vaginal sildenafil in patients with poor endometrial development undergoing in vitro fertilization. Fertil. Steril. 2004, 82, S140. [CrossRef]

29. Sher, G.; Fisch, J.D. Vaginal sildenafil (Viagra): A preliminary report of a novel method to improve uterine artery blood flow and endometrial development in patients undergoing IVF. Hum. Reprod. (Oxf. Engl.) 2000, 15, 806-809. [CrossRef]

30. Sher, G.; Fisch, J.D. Effect of vaginal sildenafil on the outcome of in vitro fertilization (IVF) after multiple IVF failures attributed to poor endometrial development. Fertil. Steril. 2002, 78, 1073-1076. [CrossRef]

31. Takasaki, A.; Tamura, H.; Miwa, I.; Taketani, T.; Shimamura, K.; Sugino, N. Endometrial growth and uterine blood flow: A pilot study for improving endometrial thickness in the patients with a thin endometrium. Fertil. Steril. 2010, 93, 1851-1858. [CrossRef]

32. Paulus, W.E.; Strehler, E.; Zhang, M.; Jelinkova, L.; El-Danasouri, I.; Sterzik, K. Benefit of vaginal sildenafil citrate in assisted reproduction therapy. Fertil. Steril. 2002, 77, 846-847. [CrossRef]

33. Fetih, A.N.; Habib, D.M.; Abdelaal, I.I.; Hussein, M.; Fetih, G.N.; Othman, E.R. Adding sildenafil vaginal gel to clomiphene citrate in infertile women with prior clomiphene citrate failure due to thin endometrium: A prospective self-controlled clinical trial. Facts Views Vis. ObGyn 2017, 9, 21-27. [PubMed]

34. Al-Assadi, A.F.; Al-Rubaye, S.A.; Laaiby, Z. The effect of Sildenafil on endometrial characters in patients with infertility. Tikrit Med. J. 2012, 18, 9.

35. Ranisavljevic, N.; Raad, J.; Anahory, T.; Grynberg, M.; Sonigo, C. Embryo transfer strategy and therapeutic options in infertile patients with thin endometrium: A systematic review. J. Assist. Reprod. Genet. 2019, 36, 2217-2231. [CrossRef] [PubMed]

36. Aboelroose, A.A.; Ibrahim, Z.M.; Madny, E.H.; Elmazzahy, A.M.; Taha, O.T. A randomized clinical trial of sildenafil plus clomiphene citrate to improve the success rate of ovulation induction in patients with unexplained infertility. Int. J. Gynaecol. Obstet. Off. Organ Int. Fed. Gynaecol. Obstet. 2020, 150, 72-76. [CrossRef] [PubMed]

37. Fahmy, A.A.; El Sokkary, M.; Sayed, S. The value of oral sildenafil in the treatment of female infertility: A randomized clinical trial. Life Sci. J. 2015, 12, 5.

38. Mangal, S.; Mehirishi, S. To study and compare the effect of vaginal sildenafil and estradiol valerate on endometrial thickness, blood flow and pregnancy rates in infertile women undergoing intrauterine insemination. Int. J. Reprod. Contracept. Obstet. Gynecol. 2016, 5, 4. [CrossRef]

39. Mohamed, T.Y. Oral sildenafil for treatment of female infertility among pco patients: Randomized comparative study. Austin J. Obstet. Gynecol. 2019, 6, 3.

40. Reddy, L.P.; Madhavi, Y.; Khan, M.I. Role of Sildenafil in ovulation induction-A comparative study of outcomes with Sildenafil in ovulation induction cycles with Clomiphene Citrate. IAIM 2016, 3, 7.

41. Vardhan, S.; Yadav, P.; Agarwal, R.; Garg, R.; Verma, U.; Pengoria, M. Effect of sildenafil citrate and estradiol valerate on endometrial characteristics in ovulation-induced cycle in women with dysovulatory infertility. J. South Asian Fed. Obstet. Gynaecol. $2019,11,3$.

42. Ataalla, W.M.; abd Elhamid, T.; Elhalwagy, A.E.E. Adjuvant sildenafil therapy in poor responders undergoing in vitro fertilization: A prospective, randomized, double-blind, placebo-controlled trial. Middle East Fertil. Soc. J. 2016, 21, 5. [CrossRef]

43. Check, J.H.; Graziano, V.; Lee, G.; Nazari, A.; Choe, J.K.; Dietterich, C. Neither sildenafil nor vaginal estradiol improves endometrial thickness in women with thin endometria after taking oral estradiol in graduating dosages. Clin. Exp. Obstet. Gynecol. 2004, 31, 99-102. [PubMed]

44. Kansouh, A.M.; El-Naggar, M.A. Value of vaginal sildenafil citrate for endometrial preparation and outcome in frozen thawed embryo transfer cycles. Med. J. Cairo Univ. 2017, 85, 7.

45. Moini, A.; Zafarani, F.; Jahangiri, N.; Jahanian Sadatmahalleh, S.H.; Sadeghi, M.; Chehrazi, M.; Ahmadi, F. The effect of vaginal sildenafil on the outcome of assisted reproductive technology cycles in patients with repeated implantation failures: A randomized placebo-controlled trial. Int. J. Fertil. Steril. 2020, 13, 289-295. [PubMed]

46. Tehraninejad, E.S.; Khazei, N.; Ayati, E.; Movafegh, A.; Azimaraghi, O. Effect of vaginal sildenafil on in vitro fertilization success rates in women with previous failed in vitro fertilization attempts. Asian J. Pharm. Clin. Res. 2018, 11, 486-488. [CrossRef]

47. Alteri, A.; Corti, L.; Cermisoni, G.C.; Papaleo, E.; Viganò, P.; Noventa, M. Busting the myth of extended blastocyst culture until Day 7: Protocol for systematic review and meta-analysis. Medicine (Baltim.) 2020, 99, e18909. [CrossRef]

48. Hromadová, L.; Tokareva, I.; Veselá, K.; Trávník, P.; Veselý, J. Endometrial Receptivity Analysis—A tool to increase an implantation rate in assisted reproduction. Ceska Gynekol. 2019, 84, 177-183. 
49. Mahajan, N.; Sharma, S. The endometrium in assisted reproductive technology: How thin is thin? J. Hum. Reprod. Sci. 2016, 9, 3-8. [CrossRef]

50. Katzorke, N.; Vilella, F.; Ruiz, M.; Krüssel, J.S.; Simón, C. Diagnosis of endometrial-factor infertility: Current approaches and new avenues for research. Geburtshilfe Frauenheilkd. 2016, 76, 699-703. [CrossRef]

51. Mahajan, N. Endometrial receptivity array: Clinical application. J. Hum. Reprod. Sci. 2015, 8, 121-129. [CrossRef]

52. Craciunas, L.; Gallos, I.; Chu, J.; Bourne, T.; Quenby, S.; Brosens, J.J.; Coomarasamy, A. Conventional and modern markers of endometrial receptivity: A systematic review and meta-analysis. Hum. Reprod. Update 2019, 25, 202-223. [CrossRef]

53. Tomic, V.; Kasum, M.; Vucic, K. Impact of embryo quality and endometrial thickness on implantation in natural cycle IVF. Arch. Gynecol. Obstet. 2020, 301, 1325-1330. [CrossRef]

54. Cozzolino, M.; Vitagliano, A.; Di Giovanni, M.V.; Laganà, A.S.; Vitale, S.G.; Blaganje, M.; Drusany Starič, K.; Borut, K.; Patrelli, T.S.; Noventa, M. Ultrasound-guided embryo transfer: Summary of the evidence and new perspectives. A systematic review and meta-analysis. Reprod. Biomed. Online 2018, 36, 524-542. [CrossRef] [PubMed]

55. Balmaceda, J.P.; Ciuffardi, I. Hysteroscopy and assisted reproductive technology. Obstet. Gynecol. Clin. N. Am. 1995, 22, 507-518. [CrossRef]

56. De Sá Rosa e de Silva, A.C.; Rosa e Silva, J.C.; Cândido dos Reis, F.J.; Nogueira, A.A.; Ferriani, R.A. Routine office hysteroscopy in the investigation of infertile couples before assisted reproduction. J. Reprod. Med. 2005, 50, 501-506.

57. Cao, H.; You, D.; Yuan, M.; Xi, M. Hysteroscopy after repeated implantation failure of assisted reproductive technology: A meta-analysis. J. Obstet. Gynaecol. Res. 2018, 44, 365-373. [CrossRef] [PubMed]

58. Dreisler, E.; Kjer, J.J. Asherman's syndrome: Current perspectives on diagnosis and management. Int. J. Womens Health 2019, 11, 191-198. [CrossRef] [PubMed]

59. Cicinelli, E.; Matteo, M.; Trojano, G.; Mitola, P.C.; Tinelli, R.; Vitagliano, A.; Crupano, F.M.; Lepera, A.; Miragliotta, G.; Resta, L. Chronic endometritis in patients with unexplained infertility: Prevalence and effects of antibiotic treatment on spontaneous conception. Am. J. Reprod. Immunol. 2018, 79, e12782. [CrossRef]

60. Cicinelli, E.; Vitagliano, A.; Kumar, A.; Lasmar, R.B.; Bettocchi, S.; Haimovich, S. Unified diagnostic criteria for chronic endometritis at fluid hysteroscopy: Proposal and reliability evaluation through an international randomized-controlled observer study. Fertil. Steril. 2019, 112, 162-173.e162. [CrossRef] [PubMed]

61. Vitagliano, A.; Saccardi, C.; Litta, P.S.; Noventa, M. Chronic endometritis: Really so relevant in repeated IVF failure? Am. J. Reprod. Immunol. 2017, 78, 28921706. [CrossRef] [PubMed]

62. Vitagliano, A.; Saccardi, C.; Noventa, M.; Di Spiezio Sardo, A.; Saccone, G.; Cicinelli, E.; Pizzi, S.; Andrisani, A.; Litta, P.S. Effects of chronic endometritis therapy on in vitro fertilization outcome in women with repeated implantation failure: A systematic review and meta-analysis. Fertil. Steril. 2018, 110, 103-112.e101. [CrossRef]

63. Griesinger, G.; Trevisan, S.; Cometti, B. Endometrial thickness on the day of embryo transfer is a poor predictor of IVF treatment outcome. Hum. Reprod. Open 2018, 2018, hox031. [CrossRef]

64. Kasius, A.; Smit, J.G.; Torrance, H.L.; Eijkemans, M.J.; Mol, B.W.; Opmeer, B.C.; Broekmans, F.J. Endometrial thickness and pregnancy rates after IVF: A systematic review and meta-analysis. Hum. Reprod. Update 2014, 20, 530-541. [CrossRef]

65. Oron, G.; Hiersch, L.; Rona, S.; Prag-Rosenberg, R.; Sapir, O.; Tuttnauer-Hamburger, M.; Shufaro, Y.; Fisch, B.; Ben-Haroush, A. Endometrial thickness of less than $7.5 \mathrm{~mm}$ is associated with obstetric complications in fresh IVF cycles: A retrospective cohort study. Reprod. Biomed. Online 2018, 37, 341-348. [CrossRef] [PubMed]

66. Lebovitz, O.; Orvieto, R. Treating patients with "thin" endometrium-An ongoing challenge. Gynecol. Endocrinol. Off. J. Int. Soc. Gynecol. Endocrinol. 2014, 30, 409-414. [CrossRef]

67. Benni, J.M.; Patil, P.A. An overview on sildenafil and female infertility. Indian J. Health Sci. 2016, 9, 6. [CrossRef]

68. Madeira, C.R.; Tonin, F.S.; Fachi, M.M.; Borba, H.H.; Ferreira, V.L.; Leonart, L.P.; Bonetti, A.F.; Moritz, R.P.; Trindade, A.; Gonçalves, A.G.; et al. Efficacy and safety of oral phosphodiesterase 5 inhibitors for erectile dysfunction: A network meta-analysis and multicriteria decision analysis. World J. Urol. 2020, 39, 953-962. [CrossRef] [PubMed]

69. Gambino, L.S.; Wreford, N.G.; Bertram, J.F.; Dockery, P.; Lederman, F.; Rogers, P.A. Angiogenesis occurs by vessel elongation in proliferative phase human endometrium. Hum. Reprod. (Oxf. Engl.) 2002, 17, 1199-1206. [CrossRef]

70. Girling, J.E.; Rogers, P.A. Recent advances in endometrial angiogenesis research. Angiogenesis 2005, 8, 89-99. [CrossRef]

71. Okada, H.; Tsuzuki, T.; Shindoh, H.; Nishigaki, A.; Yasuda, K.; Kanzaki, H. Regulation of decidualization and angiogenesis in the human endometrium: Mini review. J. Obstet. Gynaecol. Res. 2014, 40, 1180-1187. [CrossRef] [PubMed]

72. Barroso, R.P.; Osuamkpe, C.; Nagamani, M.; Yallampalli, C. Nitric oxide inhibits development of embryos and implantation in mice. Mol. Hum. Reprod. 1998, 4, 503-507. [CrossRef] [PubMed]

73. Vaughan, D.A.; Harrity, C.; Sills, E.S.; Mocanu, E.V. Serum estradiol:oocyte ratio as a predictor of reproductive outcome: An analysis of data from $>9000$ IVF cycles in the Republic of Ireland. J. Assist. Reprod. Genet. 2016, 33, 481-488. [CrossRef] [PubMed]

74. Dickey, R.P.; Taylor, S.N.; Lu, P.Y.; Sartor, B.M.; Rye, P.H.; Pyrzak, R. Relationship of follicle numbers and estradiol levels to multiple implantation in 3608 intrauterine insemination cycles. Fertil. Steril. 2001, 75, 69-78. [CrossRef]

75. Hughes, E.G.; Robertson, D.M.; Handelsman, D.J.; Hayward, S.; Healy, D.L.; de Kretser, D.M. Inhibin and estradiol responses to ovarian hyperstimulation: Effects of age and predictive value for in vitro fertilization outcome. J. Clin. Endocrinol. Metab. 1990, 70, 358-364. [CrossRef] [PubMed] 